\title{
Modulus elasticity of the graded concrete, a preliminary research
}

\author{
M. Mirza Abdillah Pratama ${ }^{1, *}$, B. Sri Umniati ${ }^{1}$, Bunga Arumsari Mutiara Wulandari ${ }^{1}$, \\ Ay Lie $\mathrm{Han}^{2}$, Buntara Sthenly Gan ${ }^{3}$, and Zhabrinna Zhabrinna ${ }^{4}$ \\ ${ }^{1}$ Department of Civil Engineering, Faculty of Engineering, Universitas Negeri Malang, Indonesia \\ ${ }^{2}$ Department of Civil Engineering, Faculty of Engineering, Diponegoro University, Indonesia \\ ${ }^{3}$ Department of Architecture, College of Engineering, Nihon University, Koriyama, Japan \\ ${ }^{4}$ School of Engineering and Physical Science, University of Birmingham, The United Kingdom
}

\begin{abstract}
The elastic modulus of materials plays a role in determining the stiffness of a structural element and its level of serviceability. Previous research indicates that the concrete modulus of elasticity could be improved by combining 2 (two) concrete mixes using a gradual compacting method. In this study, the effect of different concrete strength combinations to the resulting modulus of elasticity is examined. Three types of concrete mixes with a strength of $30 \mathrm{MPa}, 40 \mathrm{MPa}$ and $50 \mathrm{MPa}$ are prepared. The graded concrete is moulded in cylindrical concrete casts $(150 \mathrm{~mm} \times 300 \mathrm{~mm})$ with the following casting configurations: $30-40 \mathrm{MPa}, 30-50 \mathrm{MPa}$, and 40-50 $\mathrm{MPa}$. The static modulus of elasticity test is performed at an age of 28 days using compressometers in accordance with ASTM C469. The test results show that the modulus of elasticity of the graded concrete is proportionally influenced by the stiffness of the higher and the lower concrete material. Additionally, the resulting compressive strength of the graded concrete is determined by the lower concrete strength.
\end{abstract}

\section{Introduction}

Graded concrete is a unique construction material combining multiple concrete mixes to optimise the use of cement as a binding agent to achieve more sustainable construction development [1-7]. By composing distinguished concrete mixes in an element, the graded concrete members possess mechanical characteristics that vary in their elements' depth. Preliminary researches focusing on the investigation of the compressive strength of graded concrete have been conducted recently, but information about the modulus of elasticity of graded concrete is not yet widely available. As a fundamental mechanical property of the material, the modulus of elasticity of concrete should be predicted and be defined correctly provided that it affects the material stiffness and structural rigidity of an element [8-9]. Therefore, this research aims to experimentally investigate the modulus of elasticity of graded concrete at a preliminary level.

* Corresponding author: mirza.abdillah.ft@um.ac.id 


\section{Experimental programs}

In this research, an experimental program is divided into 7 (seven) steps, which are material testing, concrete mix proportioning, specimen casting and curing, hammer testing, concrete compressive testing, modulus of elasticity testing, and data analysis. The experimental test was conducted at the Laboratory of Materials Testing and the Laboratory of Structure, Department of Civil Engineering, Faculty of Engineering, Universitas Negeri Malang, Indonesia.

\subsection{Material testing}

Material characterisations aim to obtain properties of concrete materials that are further used for the concrete mix proportion. The specific gravity of Portland cement, fine aggregate, and coarse aggregate were examined along with the testing of the water content of the aggregates in a saturated-surface dry condition. All of the testing results should meet the requirement of the ASTM and Indonesian code.

\subsection{Concrete mix proportion}

Concrete mixes with compressive strengths of 30,40 and $50 \mathrm{MPa}$ were prepared in accordance with the Indonesian standard. The method was modified to accommodate the addition of superplasticizer allowing the mixes reach a minimum slump flow of $500 \mathrm{~mm}$. The fresh concrete mixes were all conditioned to have a uniformed collapse slump of $120 \mathrm{~mm}$ before adding the $0.6 \%$ of superplasticizer to the cement weight. The superplasticizer was diluted in a part of mixing water and was continuedly added to the fresh mixes while the mixing was underway. The concrete mix formulas for 30, 40 and $50 \mathrm{MPa}$ are displayed in Table 1 below.

Table 1. Concrete mix proportion.

\begin{tabular}{|c|c|c|c|c|c|}
\hline \multirow{2}{*}{$\begin{array}{c}\text { Concrete } \\
\text { strength } \\
\text { (MPa) }\end{array}$} & Cement & Water & Fine aggregate & $\begin{array}{c}\text { Coarse } \\
\text { aggregate }\end{array}$ & Superplasticizer \\
\cline { 2 - 6 } & 1.00 & 0.46 & 1.93 & 1.58 & 0.006 \\
\hline 30 & 1.00 & 0.36 & 1.38 & 1.13 & 0.006 \\
\hline 40 & 1.00 & 0.31 & 1.10 & 0.90 & 0.006 \\
\hline 50 &
\end{tabular}

\subsection{Sample preparation}

In this experimental work, the testing specimens were grouped into 2 (two) types: the graded concrete and controlling specimens. The graded concrete was prepared by composing 2 (two) concrete mixes with different strengths in a single mould. Three variables of graded concrete specimens were set up to examine the mechanical behaviour, namely G30-40, G40-50 and G30-50. G30-40 represents a graded concrete specimen composed of $30 \mathrm{MPa}$ and $40 \mathrm{MPa}$ concrete strength. The controlling specimens, namely K30, K40 and K50, were also cast to examine the compressive strength and the modulus of elasticity of normal concrete, and to compare to the graded concretes. All of the specimens were cast in $150 \times 300 \mathrm{~mm}$ cylindrical concrete moulds. Each variable is accompanied by 6 (six) pieces of specimens. Details of the concrete specimens are presented in Table 2 below. 
Table 2. Detail of concrete specimens.

\begin{tabular}{|c|c|c|c|}
\hline Notation & Number of specimens & Notation & Number of specimens \\
\hline K30 & 6 & G30-40 & 6 \\
K40 & 6 & G30-50 & 6 \\
K50 & 6 & G40-50 & 6 \\
\hline
\end{tabular}

The concrete mixing was conducted simultaneously for all of the concrete mixes after the materials were weighted. The mixing process utilized concrete mixers with a capacity of 0.03 cubic meters providing a high spinning speed to allow the superplasticizer to react optimally with the concrete mixes. The concrete mixing was carried out in accordance with the Indonesian standard. The slump flow test was conducted to the concrete mixes to assure the minimum flow number was achieved. The procedure of this test complies with the instruction in ASTM C1611. In this work, every concrete mix satisfied the requirement of slump flow of $500 \mathrm{~mm}$ and was all set for concrete casting.

Before the concrete casting, the inner parts of the moulds were lubricated using grease to ease the de-moulding process. Straightforward concrete casting methods were adapted to the normal concrete as instructed in ASTM C192. For the graded concrete specimens, the concrete casting was initiated by situating the higher concrete strength at the bottom part of the moulds, and the lower strength at the upper layer. Incremental compaction as suggested by Gan was applied to the specimens. The tamping procedure is intended to create a smooth strength transition in the specimens and to diminish cold-joints between two distinguished concrete mixes. A perforated steel plate with a set of tamping rods was utilised for the compaction. All of the concrete specimens were de-moulded 24 hours after casting. Concrete curing was applied to the specimens by submerging them in a water pond for 20 days. After the curing period, the specimens were air-dried indoors for another 8 (eight) days before laboratory testing.

\subsection{Testing set-up}

The hammer test was conducted on the graded concrete specimens in order to predict the compressive strength by the incremental depth. The data reading was performed at different depths, which were 30, 90, 150, 210 and $270 \mathrm{~mm}$ from the bottom. The testing location was spotted using a marker on the surface to ease the test. The concrete strength prediction was presented by 9 (nine) repetitions of reading in the same depth. The specimens were set up in the Universal Testing Machine and were compressed with a load of 4.2 MPa. The hammer test was performed using Schmidt hammer apparatus with a reading angle of $0^{\circ}$. The resulting rebound numbers were recorded and were converted to obtain the concrete strength prediction.

The modulus of elasticity test was conducted simultaneously with the compression test using the Universal Testing Machine after the hammer test was completed. The compression test is performed in accordance with ASTM C39/C39M, while the modulus of elasticity follows ASTM C469. Compressometers were attached to the concrete cylinders and the alignment was set. The incremental displacement and loads during the test are recorded and further analysed to generate the concrete stress-strain diagram. 


\section{Results and discussion}

\subsection{Hammer test}

Figure 1 demonstrates that all of the graded concrete specimens have an identical data trend wherein the compressive strength levels decrease along with the increase in the specimens' depth. This agrees with the concrete casting set up which situated the higher concrete strength at the bottom and layered the lower concrete strength at the upper part of the moulds. The graph also presents that mechanical compaction is proven to create a good concrete strength transition. There is no strength leap along the specimens' height. In this research work, the hammer test is only intended to assess the effectiveness of the compaction method because it is not a standard procedure used to acquire the compressive strength of concrete. The reading of the rebound number is highly influenced by the hardness of the concrete surface and also by the distribution of concrete material beneath the examined points.

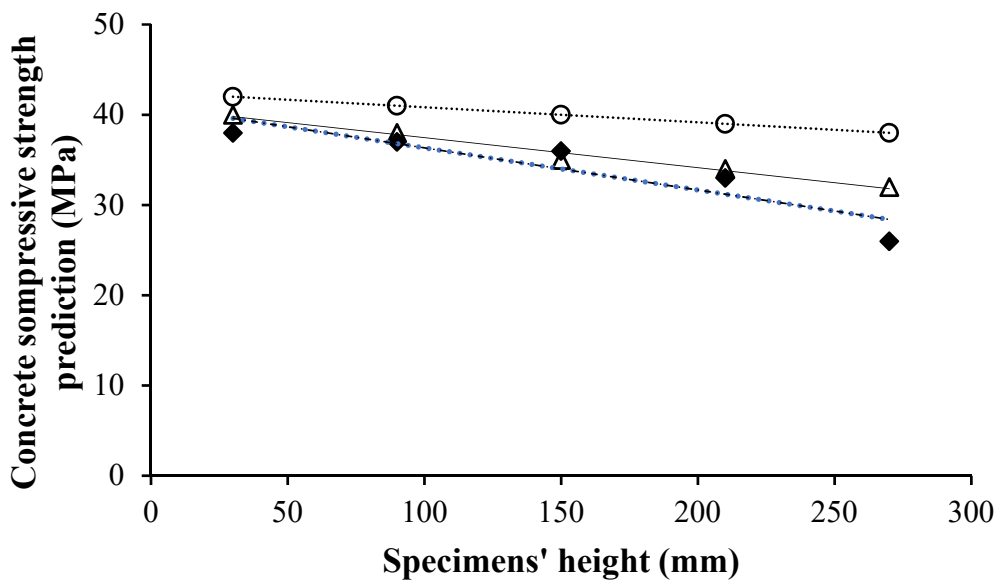

Fig. 1. Concrete strength distribution of graded concrete.

\subsection{Concrete compressive strength}

Table 3 shows that the graded concrete reaches a compressive strength that leans towards the lower concrete strength. This complies with the findings of the research conducted by Gan and Pratama stating that the lowest concrete strength determines the ultimate compressive strength of the specimens.

Table 3. Mean concrete compressive strength.

\begin{tabular}{|c|c|c|c|}
\hline $\begin{array}{c}\text { Specimens' } \\
\text { type }\end{array}$ & $\begin{array}{c}\text { Mean concrete } \\
\text { compressive } \\
\text { strength (MPa) }\end{array}$ & $\begin{array}{c}\text { Specimens' } \\
\text { type }\end{array}$ & $\begin{array}{c}\text { Mean concrete } \\
\text { compressive } \\
\text { strength } \\
\text { (MPa) }\end{array}$ \\
\hline $\mathrm{K}_{30}$ & 34,35 & $\mathrm{G}_{30-40}$ & 35,12 \\
\hline $\mathrm{K}_{40}$ & 46,81 & $\mathrm{G}_{30-50}$ & 36,36 \\
\hline $\mathrm{K}_{50}$ & 56,99 & $\mathrm{G}_{40-50}$ & 49,07 \\
\hline
\end{tabular}

The data are transformed into a graph representing a comparison of the compressive strength of the graded concrete and the normal concrete. The data is then normalized by 
dividing the compressive strength of each group with the lowest constitutive concrete strength. The lowest compressive strength of each group is associated with a ratio $=1$. The graph of the concrete compressive strength ratio is shown in figure 2.

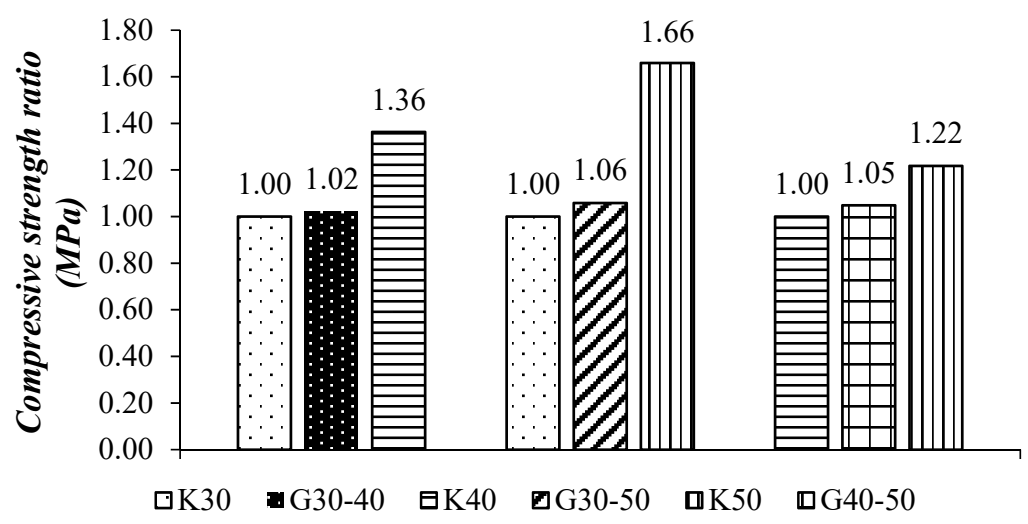

Fig. 2. Concrete compressive strength ratio.

The concrete compressive strength ratio of G30-40, G30-50 and G40-50 to the lowest concrete strength is $1.02,1.06$ and 1.05 , respectively, meaning that the compressive strength of the graded concrete increases from $2 \%$ to $6 \%$ to their lowest concrete strength constituent. From the data, the analyses could be extended to understand the influence of the concrete strength disparity of graded concrete to the increments in compressive strength. Figure 3 demonstrates that the graded concrete strength increases by the increase of the concrete strength disparity on the specimens. The graded concrete strength increases approximately $7 \%$ by the $70 \%$ of the concrete disparity.

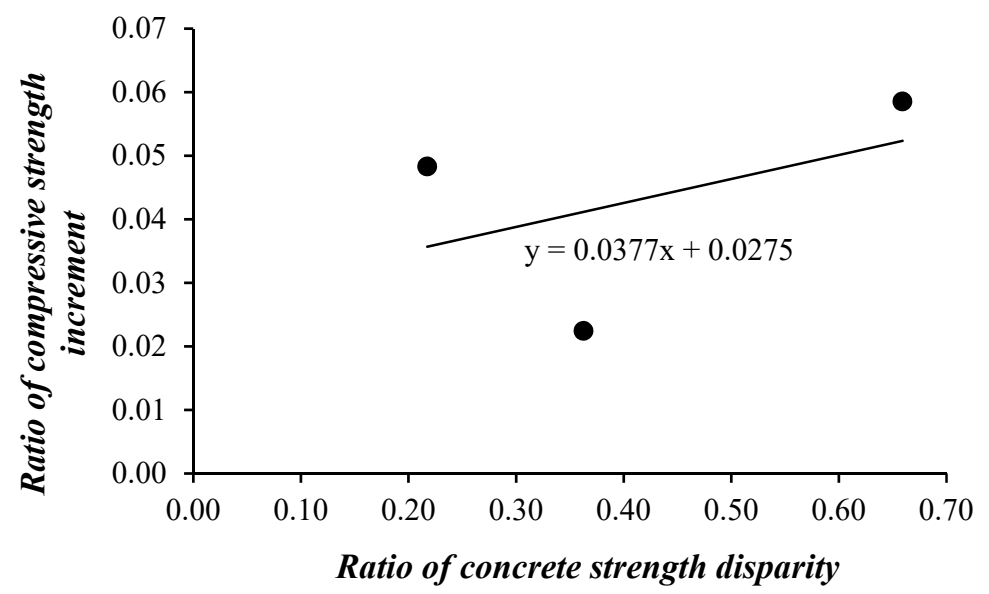

Fig. 3. Effect of concrete strength disparity to the resulting compressive strength.

\subsection{Concrete modulus of elasticity}

Incremental loads and displacements from the load cell and compressometer are transformed into a stress-strain graph by dividing the data with the area and the initial length of the cylindrical concrete specimens. The stress-strain relationship of each graded concrete and the controlling specimens are shown in figure 4 . Figure 4 shows that the higher the compressive 
strength of normal concrete, the initial stiffness of concrete increases by the function of its compressive strength. At the same level of stress, the graded concrete creates a steeper slope than the normal concrete. This indicates that the graded concrete provides a higher modulus of elasticity and a higher stiffness. In terms of material ductility, the graded concrete shows slightly more brittle behaviour indicated by the post-peak pattern that discontinues in a shorter deformation after the peak state. A recapitulation of the stress-strain graph of the testing specimens is displayed in Figure 4.

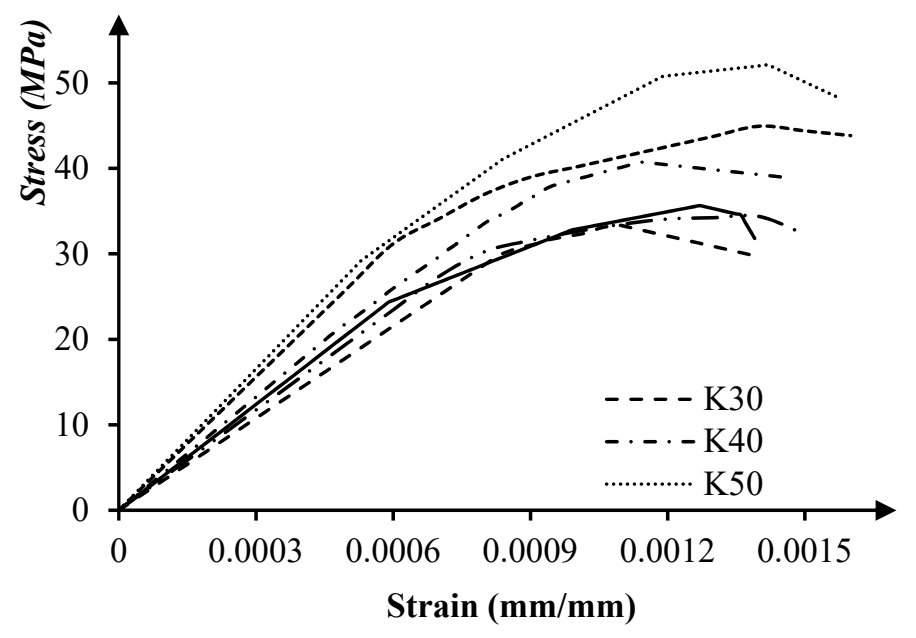

Fig. 4. Stress-strain relationship of normal and graded concrete.

The static modulus of elasticity is observed from the stress-strain relationship in a state of linear conditions. The initial tangent modulus is obtained by dividing $40 \%$ ultimate stress to their corresponding strain. The static modulus of elasticity of each specimens' group is shown in Table 4.

Table 4. Modulus of elasticity

\begin{tabular}{|c|c|c|c|}
\hline $\begin{array}{c}\text { Specimens' } \\
\text { type }\end{array}$ & $\begin{array}{c}\text { Modulus of elasticity } \\
\text { (MPa) }\end{array}$ & $\begin{array}{c}\text { Specimens' } \\
\text { type }\end{array}$ & $\begin{array}{c}\text { Modulus of elasticity } \\
\text { (MPa) }\end{array}$ \\
\hline $\mathrm{K}_{30}$ & $35,714.3$ & $\mathrm{G}_{30-40}$ & $40,000.0$ \\
\hline $\mathrm{K}_{40}$ & $44,444.4$ & $\mathrm{G}_{30-50}$ & $40,816.3$ \\
\hline $\mathrm{K}_{50}$ & $55,555.6$ & $\mathrm{G}_{40-50}$ & $50,000.0$ \\
\hline
\end{tabular}

The modulus of elasticity of graded concrete and the controlling specimens are grouped into 3 (three) different clusters as presented in figure 6 . The data was standardized by dividing the modulus of elasticity by the highest number in each group. This consideration is taken into account due to the previous assumption stating that the modulus of elasticity of the graded concrete is determined by the highest concrete strength. The calculation shows that the modulus of elasticity of K40 and K50 equals 1, and the modulus of elasticity of G30-40 G30-50 and G40-50 are 0,90, 0,73, and 0,90 respectively.

From the standardized graph in figure 5, it is understood that the resulting modulus of elasticity of graded concrete is proportionally influenced by both of the constitutive concrete strengths, which are the lowest and highest concrete strengths. This revises former findings stating that the modulus of elasticity of graded concrete only determines the highest concrete strength. 


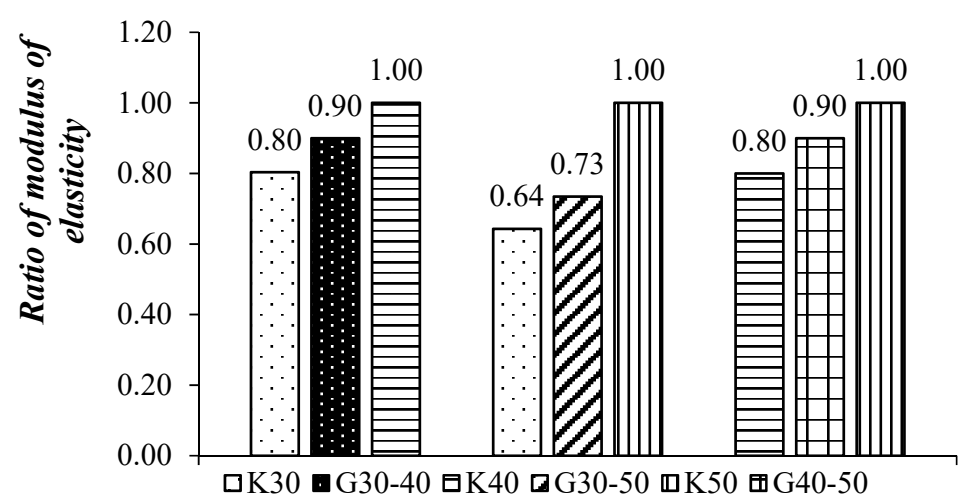

Fig. 5. The ratio of the modulus of elasticity of graded concrete to the constitutive concrete mixes.

Further analysis could be drawn by correlating the influence of the concrete strength disparity to the increase of modulus of elasticity of the graded concrete. The increase of the strength disparity will result in the decrease of the resulting concrete modulus of elasticity. In this experimental work, $70 \%$ of concrete disparity in graded concrete could drop the modulus of elasticity up to $10 \%$. This is because the strength disparity leads to stress discontinuity in the concrete specimen and effects the material resistance in withstanding compressive strength. The large disparity results in early cracking of the concrete specimen and reduces the stiffness of the material.

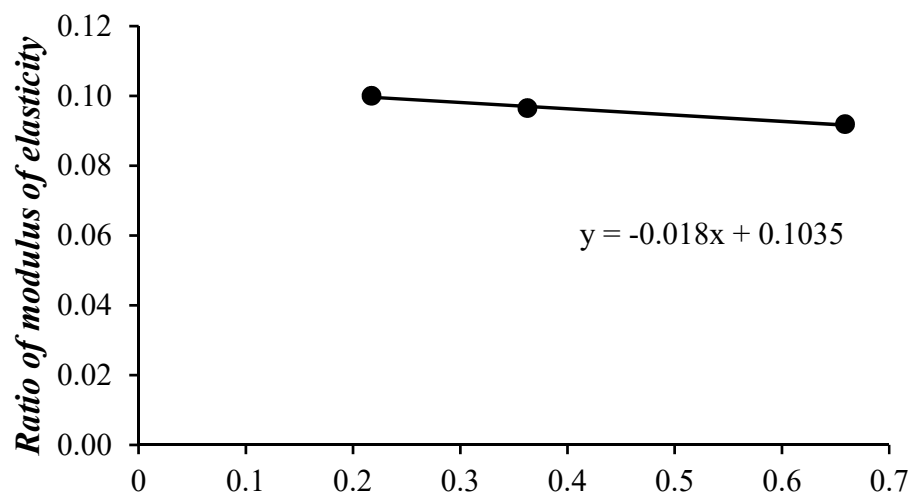

Ratio of concrete strength disparity

Fig. 6. Effect of concrete strength disparity to the increase of modulus of elasticity.

\section{Conclusions}

From this research work, the researchers conclude the findings into 4 (four) major points:

- The compressive strength of graded concrete is determined by the contribution of the lowest concrete strength. An addition to higher compressive strength does not provide a substantial increase in compressive strength.

- The modulus of elasticity of graded concrete is proportionally influenced by both concrete compositions, meaning that graded concrete inherits the characteristics of its constituents, each by half.

- The concrete strength disparity increases the resulting graded concrete strength. 
- The strength disparity in graded concrete results in the decrease of the modulus of elasticity due to premature cracking at the beginning of loading.

Researchers wish to acknowledge PT. Sika Indonesia and PT. BASF Indonesia for providing material support during the research.

\section{References}

1. H. Ay Lie, B.S. Gan, S. As'ad, and M.M.A. Pratama, Int. J. Eng. Technol. Innov. 5, 233, (2015)

2. M. Mirza Abdillah Pratama, H. Ay Lie, B. Sthenly Gan, B. Sri Umniati, P. Risdanareni, and S. Fauziyah, AIP Conf. Proc. 1887, (2017)

3. A.L. Han, B.S. Gan, and M.M.A. Pratama, Int. J. Technol. 7, 732, (2016)

4. B.S. Gan, H. Ay Lie, and M.M.A. Pratama, in Procedia Eng., 885-891, (2015)

5. Sulistyana, Purwanto, V. Widoanindyawati, and M.M.A. Pratama, in Procedia Eng., 465-472, (2014)

6. A. Hidayat, P. Purwanto, J. Puspowardojo, and F.A. Aziz, in Procedia Eng., 1023-1029, (2015)

7. M.M.A. Pratama, An Experimental Study and Finite Element Approach to the Behavior of Graded Concrete, September 2015, DOI10.13140/RG.2.1.4082.4568, Thesis for: Master of Engineering, Universitas Diponegoro, Indonesia, (2015)

8. K.K. Sideris, P. Manita, and K. Sideris, Cem. Concr. Compos. 26, 623, (2004)

9. M. Nematzadeh and M. Naghipour, Constr. Build. Mater. 34, 476, (2012) 